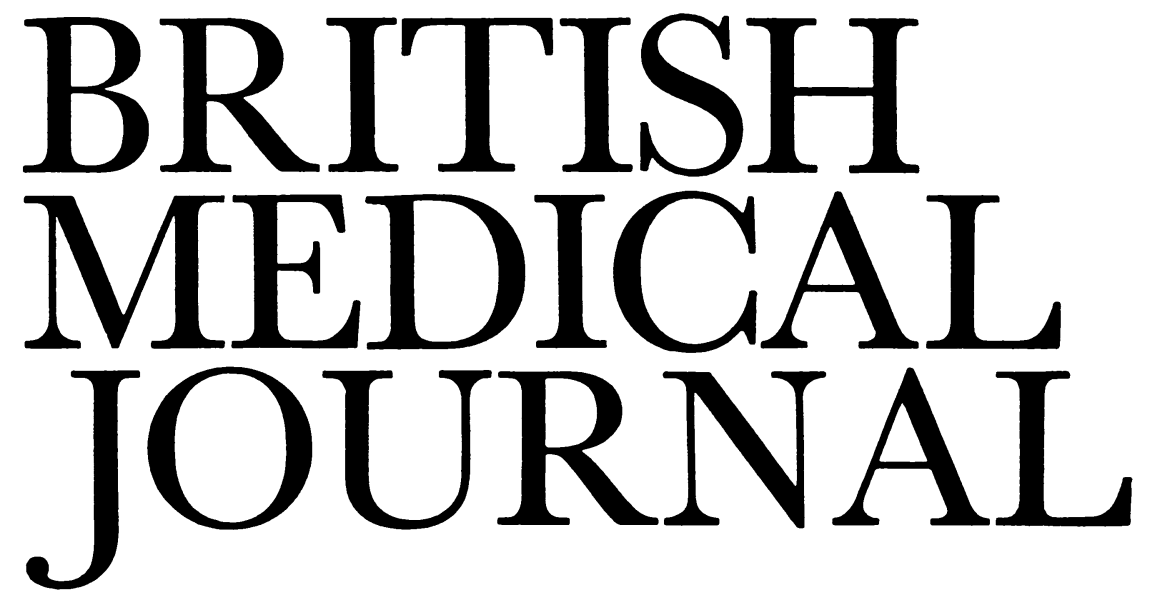

LONDON, SATURDAY 2 AUGUST 1986

\title{
The lessons from the Savage inquiry
}

Early in the development of the English common law a mediaeval lawyer laid down the doctrine that the courts could not hope to determine "what lay in the mind of a man." So despite a prolonged inquiry and vast amounts of journalistic speculation no one but those concerned can know how and why charges of incompetence came to be laid against $\mathrm{Mrs}$ Wendy Savage, senior lecturer in obstetrics at the London Hospital. Furthermore, the bulk of the inquiry's report is not being published for reasons of confidentiality. What can be said-for the inquiry tribunal decided the issue as a matter of fact-is that Mrs Savage's academic chief Professor Jurgis Grudzinskas had determined shortly before taking up his appointment to "change his senior lecturer." The charges of incompetence came later, and these have now been rejected and Mrs Savage reinstated (see p 340 and letter from the Medical Protection Society on p 338).

Medicine is a fallible business: patients die, and with the benefit of hindsight many clinical decisions may be seen to have been mistaken, or delayed, or less than optimal. So in the eyes of his peers a consultant who makes mistakes may not necessarily be seen as incompetent, though some are clearly better technicians or diagnosticians than others. Nevertheless, in some circumstances a consultant's decisions will come under sustained criticism by his or her colleagues in the same specialty - those who share arrangements for cover. Sometimes the consultant concerned has a drink problem or is sick-and procedures exist for dealing with such cases; they are being improved, but they are still far from perfect. On rare occasions a consultant may be repeatedly unavailable, late for sessions, or otherwise in obvious breach of contract; here the health authority has a duty to enforce the contract of employment. The most difficult problem in terms of competence occurs when one consultant has developed an individual approach to the management of his or her patients that is out of line with the views of the others. If this view is sincerely held, thought through, and supportable by published evidence it cannot be described as incompetent-but it will cause difficulties. And if the individual approach is outside the range of acceptable clinical variation the difficulties will be substantial. In both circumstances the differences of opinion need to be resolved -in the interests of patients, of harmonious working conditions, and of a consistent clinical policy to be followed by junior staff. Ideally a consensus should be reached within the division of medicine, surgery, or whatever; if the consultants appear reluctant to discuss their differences the new Griffiths managers should, perhaps, take on the task of requiring them to do so.

Mrs Savage was not, however, incompetent; indeed, she had many witnesses to her dedication and commitment to the welfare of her patients. If it achieved nothing else the publicity culminating in the inquiry has exposed to the public view many more examples of consultants being suspended by health authorities as a result of complaints by colleagues. By coincidence this month another consultant, Dr Royce Darnell, dismissed after an inquiry under the same procedure as that used in the Savage case, has won his claim for judicial review (see p 322). In most cases-whatever the allegations may be-the prime issue seems to be an irreconcilable clash of personalities. In those circumstances health authorities seem ready to accept a convenient formula of suspension merging imperceptibly into early retirement. The suspended consultant is banished from his hospitalfrom his records, his secretary, and any colleagues who support him. Little wonder that many seem to have given up hope and accepted the terms offered. Mrs Savage was fortunate that her university appointment gave her continued right of entry to the London Hospital. She was unusual in being prepared to stand up and fight. She has now been vindicated in her claim that the charges of incompetence could not be proved. Plainly she and her colleagues did not see eye to eye. Mrs Savage's strongly held and voiced opinions on women's rights to a say in their method of delivery and in their rights to abortion made her a public and at times controversial figure; rumours of other sources of conflict with her colleagues have ranged from style of dress to private practice. Inevitably when there is personal antagonism or antipathy any differences of opinion on clinical issues will prove difficult to resolve. Nevertheless, an effort could and should have been made to reconcile the clinical differences - which were by no means irreconcilable. Why the health authority chose to set up the inquiry rather than attempt conciliation is another question that will remain unanswered.

Nor does the medical establishment come out of the affair with its reputation enhanced. Michael O'Donnell went on record in September 1985 and May 1986 as being appalled by the innuendos and "quiet words in the ear" circulating in 
high places. ${ }^{12}$ The medical profession still behaves on occasions like an Edwardian gentlemen's club, concerned to close ranks against anyone with non-conformist tendencies and taking on faith the integrity of "clubbable" individuals.

So what lessons should be learnt from an affair that has cost round $£ 300000$ and caused great distress to many patients, doctors, midwives, and ordinary citizens of Tower Hamlets?

Firstly, the NHS should develop some machinery for resolving conflicts between consultants when these are based on clashes of personality. Perhaps there should be a mediation procedure using a professional arbitrator with counselling skills.

Secondly, managers should ensure that each division within a district hospital has a consistent, agreed policy for dealing with contentious clinical issues and especially with those emergencies and decisions for which cross cover has to be arranged. Junior staff should not have to try to remember which consultant requires which approach; the approach should be uniform.

Thirdly, deaths and disaster meetings should be held regularly in all divisions so that any suspicions of inappropriate management are aired and discussed within a week or two of the event.

Finally, London University and the Royal College of Obstetricians and Gynaecologists-both of whom were well aware of the conflicts long before they came to a head-might ask themselves whether their studied refusal to become involved might not have been mistaken. Someone somewhere should have acted sooner to attempt the reconciliation that will now be so much more difficult.

1 O'Donnell M. One man's burden. Br Med f 1985;291:746.

2 O'Donnell M. One man's burden. Br Med F 1986;292:1282.

\section{Hazards of bronchoscopy}

The introduction of the flexible bronchoscope in 1968 heralded a rapid increase in the number of diagnostic bronchoscopies, most of them performed under local anaesthesia by respiratory physicians. For visible tumours fibreoptic bronchoscopy yields more positive biopsy specimens, particularly from the upper lobe bronchi, than rigid bronchoscopy. ${ }^{1-3}$ Transbronchial lung biopsy through a fibreoptic bronchoscope often provides a positive histological diagnosis in patients with diffuse pulmonary disease, such as sarcoidosis, fibrosing alveolitis, and carcinomatosis, ${ }^{+}$ whereas transthoracic needle biopsy has high failure and complication rates. ${ }^{5}$ In contrast, transbronchial biopsy is much less successful than needle biopsy in obtaining tissue from peripheral tumours, ${ }^{56}$ though the yield may be increased slightly by cytological examination of bronchial brushings.

Fibreoptic bronchoscopy and transbronchial lung biopsy are convenient to perform and well tolerated by most patients, but there has been a tendency to discount their potential hazards. A survey of bronchoscopic practice in Britain during 1983 has exposed these hazards. ${ }^{7}$ A $90 \%$ response to the postal questionnaire, which was sent to all 440 respiratory physicians in Britain thought likely to be performing bronchoscopy, showed that at least 40000 bronchoscopies ( $87 \%$ with the fibreoptic instrument) had been performed in 1983 compared with an estimated 15000 in 1974. The mortality for fibreoptic bronchoscopy alone was $0.04 \%$, with an incidence of major complications of $0 \cdot 12 \%$; the figures for transbronchial lung biopsy were considerably higher $(0 \cdot 12 \%$ and $2 \cdot 7 \%$ respectively). These figures might well be underestimates since some less successful bronchoscopists (including perhaps most of the $10 \%$ of non-respondents) may have been reluctant to report deaths and major complications.

Fibreoptic bronchoscopy itself has two potential dangershaemorrhage after biopsy of a tumour and an increase in airflow resistance caused by what is in effect a foreign body in the main airway. ${ }^{8}$ The latter is particularly apt to produce hypoxaemia, and in some cases hypercapnia, in patients with chronic bronchopulmonary disease. This is especially likely if they are oversedated for the procedure, particularly with

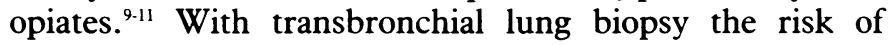

haemorrhage is greater, and there is the additional complication of pneumothorax should the biopsy forceps penetrate the visceral pleura.

The authors of the report emphasise that precautions that could prevent deaths and reduce major complications are often inadequate. Haemorrhage after biopsy, if more than slight, is an alarming and dangerous complication of fibreoptic bronchoscopy: vision is obscured, and the suction channel is too narrow to remove large amounts of blood. The only secure way to cope with moderate or severe bleeding and prevent asphyxia is to insert a rigid bronchoscope and keep removing the blood through a wide bore aspirating tube until the haemorrhage stops. Unfortunately, few younger respiratory physicians have the skill to pass a rigid bronchoscope rapidly in an emergency, and so the risk of death from haemorrhage related to biopsy may increase. Important hypoxaemia during and after fibreoptic bronchoscopy under local anaesthesia may be prevented by care in using sedation and by giving oxygen..$^{912}$ These precautions are vital in patients with respiratory insufficiency, who can and should be identified by arterial blood gas studies before bronchoscopy is undertaken. Since hypoxaemia puts patients at risk of cardiac arrest, equipment for resuscitation should be close at hand. Surprisingly, local anaesthetic agents seldom appear to produce toxic effects even when delivered (as they often are) in excessive dosage: half or more of the anaesthetic solution may be removed by suction.

The incidence of pneumothorax after transbronchial lung biopsy may be reduced substantially (from $2.9 \%$ to $1.8 \%$, the report says) by radioscopic monitoring of the procedure. This should now be mandatory. A chest radiograph should always be taken before the patient is returned to the ward, and equipment for inserting an intercostal tube should be immediately available.

The explosive increase in the number of fibreoptic bronchoscopies between 1974 and 1983 must have been due mainly to more ready recourse to bronchoscopy in patients with suspected lung cancer. In principle, that is admirable, but perhaps too many high risk patients-the elderly, the frail, and those with advanced chronic obstructive airways disease-are now being subjected to an invasive 